\title{
Effects of Injection Nozzle Geometry on Spray Characteristics for Direct Injection Diesel Engines
}

\author{
Nobushige Tamaki ${ }^{* 1}$, Takato Harada ${ }^{2}$ \\ ${ }^{1}$ Technical Research Institute of Kindai University, Japan \\ ${ }^{2}$ Graduate School of Kindai University, Japan \\ *Corresponding author: tamaki@hiro.kindai.ac.jp
}

\begin{abstract}
The purpose of this study is to improve the spray characteristics of a direct injection Diesel nozzle. Spray atomization of the multi-hole atomization enhancement nozzle, which was invented in previous studies, is explored. The aim is to improve and obtain excellent spray characteristics. The effects of different nozzle geometries and dimensions on spray characteristics are investigated, including chamfered and rounded nozzle hole inlets and a multi-hole atomization enhancement nozzles. It is found that the multi-hole atomization enhancement nozzle with a rounded chamfered inlet is effective in achieving a high-dispersion spray, a large spray angle and small droplets. However, it should be noted that the spray is significantly atomized and a large number of small droplets as suspended as a mist. The photographic images of the spray are taken against a white background and the boundaries between the ejected spray and the background are indistinct. Furthermore, the breakup length is short at $3 \mathrm{~mm}$ for a hole diameter of $0.3 \mathrm{~mm}$, the spray angle is about $70^{\circ}$ and the Sauter mean diameter decreases dramatically to $15 \mu \mathrm{m}$ at a low injection pressure of $10 \mathrm{MPa}$.
\end{abstract}

Keywords: Atomization, Diesel Engine, Spray Characteristics, Injection Nozzle, Cavitation

\section{Introduction}

It is necessary to reduce carbon dioxide $\left(\mathrm{CO}_{2}\right)$ emissions to control its effect on global warming. To this end, a direct injection (D.I.) Diesel engine offers the highest thermal efficiency and a low fuel consumption rate. In order to improve combustion efficiency and exhaust gas characteristics and to further reduce the fuel consumption rate of the D.I. Diesel engine, the aim of this research is to improve the spray characteristics of the fuel spray. In recent years, automobile manufacturers have demanded the development of a Diesel injection nozzle that makes leanburn combustion possible. The final objectives of this study include improving the combustion characteristics of the D.I. Diesel engine, reducing exhaust gas emissions, and improving the engine's thermal efficiency and fuel consumption rate by developing the desired injection nozzle and its spray characteristics.

In previous studies conducted by the authors, it was found that the proposed atomization enhancement nozzle, in which cavitation occurs in the nozzle hole and a strong disturbance is produced in the liquid flow in the nozzle hole, yielded excellent spray characteristics. It was also found that cavitation phenomena in the nozzle hole considerably affected the atomization of the spray [1]-[7].

This study focuses on improving the atomization of the multi-hole nozzle and improving the spray characteristics of the D.I. Diesel nozzle. The engine's nozzle hole inlet is chamfered and rounded to improve flow characteristics. However, it is well known that, although this leads to a larger discharge coefficient, the spray characteristics become poor unless the injection pressure is increased significantly. Therefore, the effects of different nozzle geometries and dimensions on spray characteristics were investigated.

This includes chamfered and rounded nozzle hole inlets and multi-hole nozzles, which were invented in previous studies. By using a multi-hole nozzle to separate one nozzle hole into four nozzle holes, an atomization enhancement nozzle can be achieved, with a high-dispersion and high-efficiency spray and improved spray and flow characteristics [8], [9].

It is found that for the case where the multi-hole atomization enhancement nozzle inlet was chamfered and rounded, the breakup length is reduced by $10 \%$ and the spray angle increases by $20 \%$ compared to a sharp edged nozzle inlet. The spray angle for the rounded chamfered inlet is about $70^{\circ}$ and the Sauter mean diameter is decreased to $15 \mu \mathrm{m}$ at a low injection pressure of $10 \mathrm{MPa}$.

\section{Apparatus and methods}

A schematic of the experimental apparatus is shown in Fig.1. The equipment consisted of a high-pressure pump that was controlled by an air compressor, a spark light source for photographing the spray, a screen detector for measuring the breakup length and an LDSA particle analyser for measuring the droplet size and its distribution. 
Room-temperature water, which was pressurized by a high-pressure pump, was continuously injected under atmospheric pressure conditions. The maximum injection pressure was $10 \mathrm{MPa}$, and experimental data is discussed at spray region. Based on the results of previous studies, the injection pressure inside the spray region is estimated to be over about $5 \mathrm{MPa}$ for a hole diameter of $0.3 \mathrm{~mm}$.

In this work, the maximum injection pressure is $10 \mathrm{MPa}$, the ambient pressure is atmospheric pressure condition of $0.1 \mathrm{MPa}$, steady state injection and test liquid is water, they are quite far from an actual Diesel application. These reasons are as follows. In the previous studies [2], [4]-[7], the spray of the nozzles, which were designed and invented in this study, atomizes significantly and excellent spray characteristics i.e. the spray angle is large, the breakup length is short and the Sauter mean diameter is small, were obtained at the low injection pressure of 15 $\mathrm{MPa}$ and $20 \mathrm{MPa}$ independent of the injection pressure, the ambient pressure, kinematic viscosity and injection style. Spread of the spray at the injection pressure of $10 \mathrm{MPa}$ was wide compared with one of the injection pressure of $200 \mathrm{MPa}$ [4]. Moreover, the results and tendencies obtained at steady state injection were almost same at intermittent injection [7]. Furthermore, excellent spray characteristics were obtained, even though high-viscosity liquid i.e. correspond to the heavy oil was used [6]. Therefore, on a basis of these results, backgrounds and possibility of easy measurement, the authors studied these conditions [See Appendix Figs. 1 - 7].

The disintegration behavior of the spray was studied by photographing the scattered light using the stroboscope. The breakup length of a liquid core, defined as the distance from the exit point of the nozzle to the breakup point of the liquid core, was measured using an electrical resistance method. The spray angle was defined as the angle of the outer edge of the spray. Droplet size distributions were measured $100 \mathrm{~mm}$ downstream from the exit point of the nozzle using the LDSA particle analyzer based on a narrow-angle forward-scattering technique.

Where, an aspect of the LDSA particle analyzer is shown in Fig.2, and a schematic of the narrow-angle forwardscattering technique is shown in Fig.3. Mean droplets diameter of the spray was calculated automatically by

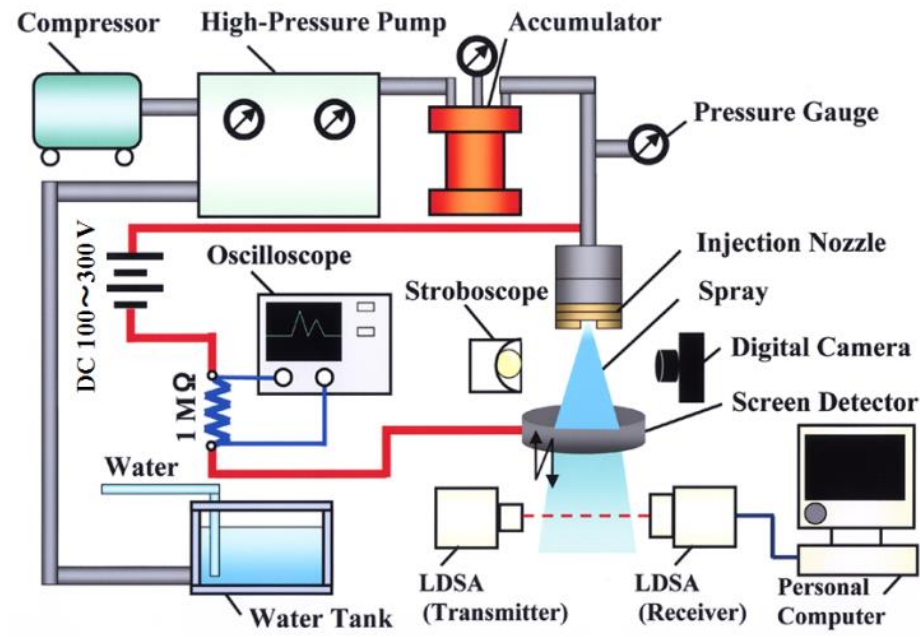

Figure 1. Schematic of experimental apparatus.

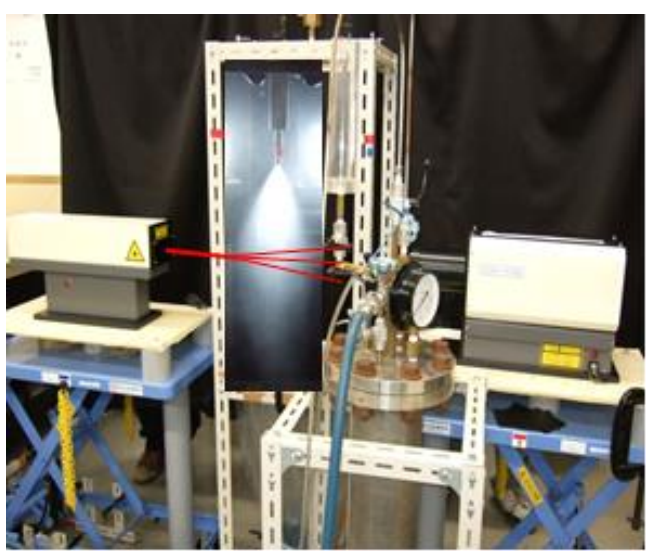

Figure 2. Aspect of LDSA particle analyzer.
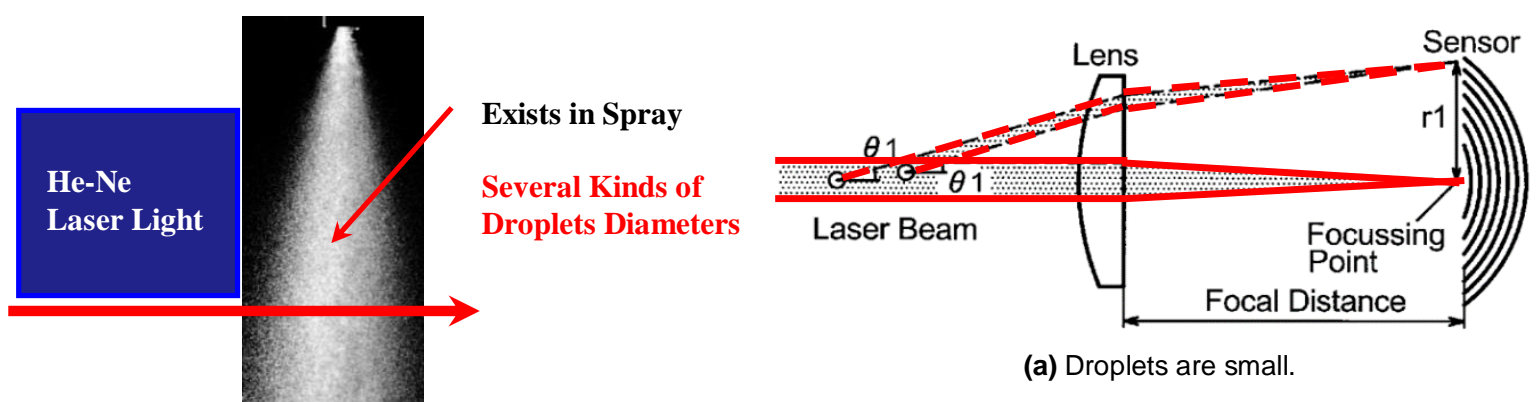

(a) Droplets are small.
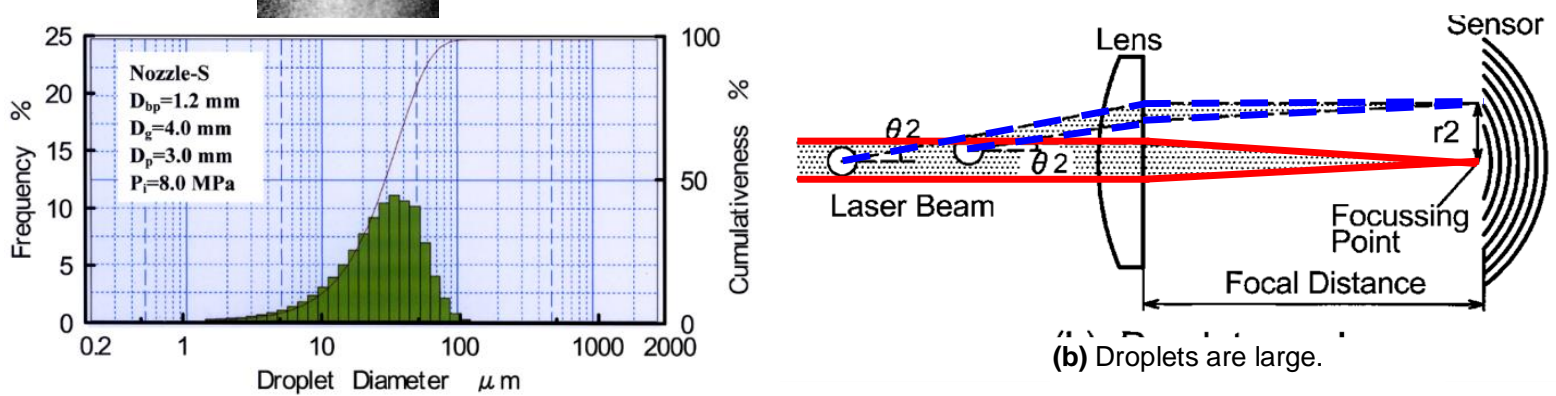

(b) Droplets' are large.

Figure 3. Schematic of narrow-angle forward-scattering technique.

This work is licensed under a Creative Commons 4.0 International License (CC BY-NC-ND 4.0). 
analyzing software, which is installed at the LDSA. It gives the Sauter mean diameter $\mathrm{D}_{32}$ that is spatially averaged along a line through the spray. There are several kinds of droplets in the spray. When He-Ne laser light was radiated the small droplet, it was refracted to large angle [Fig.3 (a)]. To the contrary, when laser light was radiated the large droplet, it was refracted to small angle. Radiation light from the spray droplets condensed at a receiver of the LDSA. The Sauter mean diameter $\mathrm{D}_{32}$, which is important for fields of spray combustion and which is defined as ratio of volume of droplets to surface area of its, were calculated by the LDSA particle analyzer.

The appearance and a schematic of an injector for the D.I. Diesel engine are shown in Figs. 4 and 5, respectively. The atomization enhancement nozzle consists of a bypass, a gap and nozzle holes. The gap is located in the middle of the nozzle hole. The bypass is a hole, connected between the upstream chamber, which corresponds to the sac chamber of an actual Diesel injector and the gap. The role of the bypass is to increase the pressure in the gap to cause the collapse of cavitation bubbles. The swirling flow is believed to be caused by the liquid flow in the bypass.

Three-dimensional images and a schematic of a test nozzle are shown in Fig.6. The test nozzles used included a nozzle with a sharp edged inlet (called Nozzle-S, S), nozzles with a rounded chamfered inlet or outlet (called Nozzle-

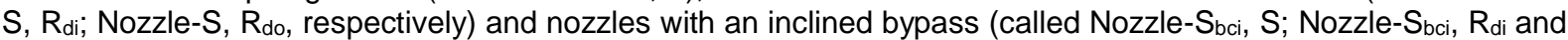
Nozzle-Sbci, Rdo, respectively).

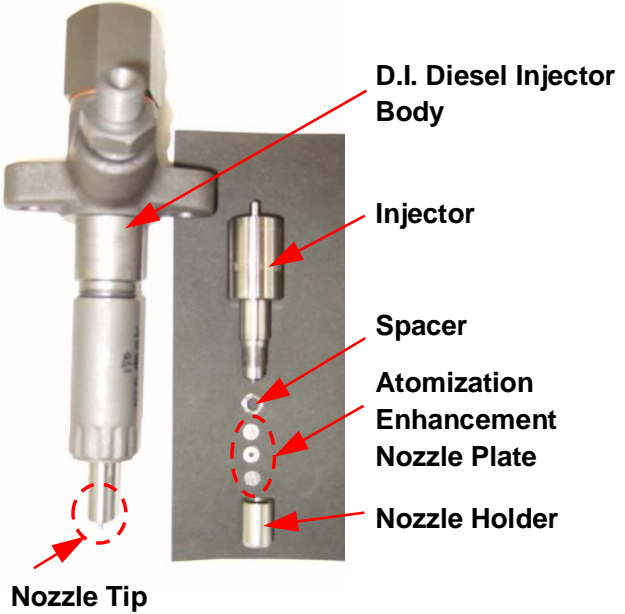

Figure 4. Appearance of injector for D.I. Diesel engine.

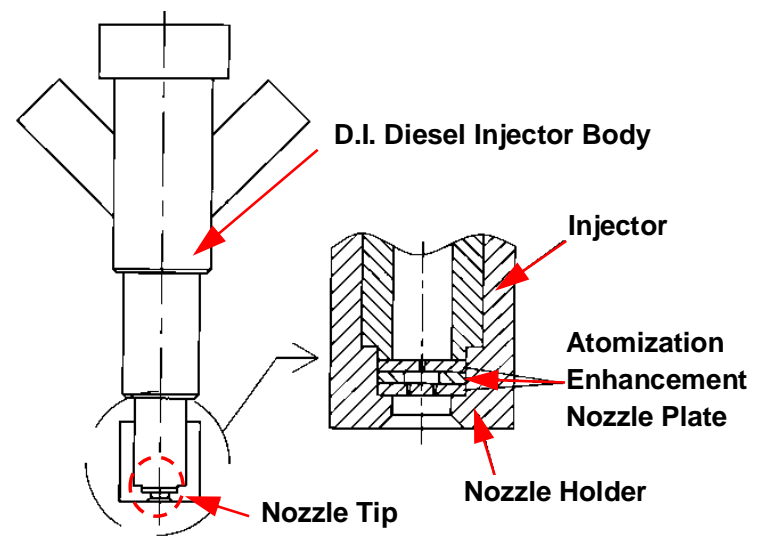

Figure 5. Schematic of injector for D.I. Diesel engine.

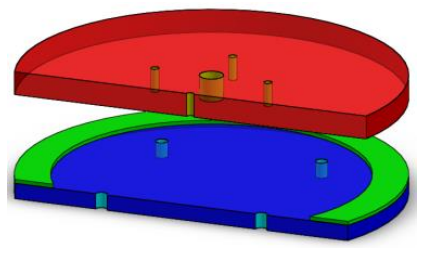

(a) Nozzle-S, S

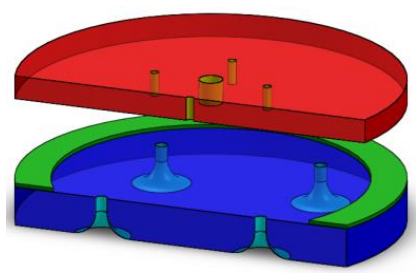

(c) Nozzle-S, $R_{\text {do }}$

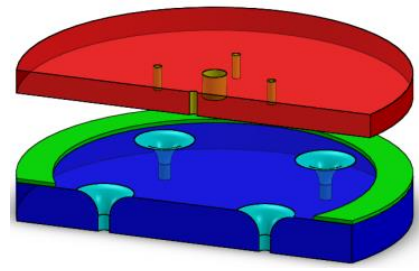

(b) Nozzle-S, $R_{\mathrm{di}}$

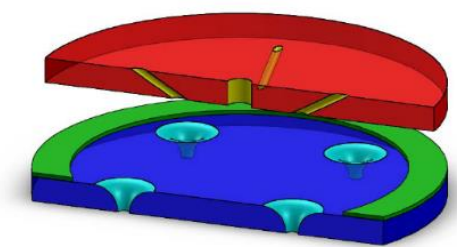

(d) Nozzle-S $S_{b c i}, R_{d i}$

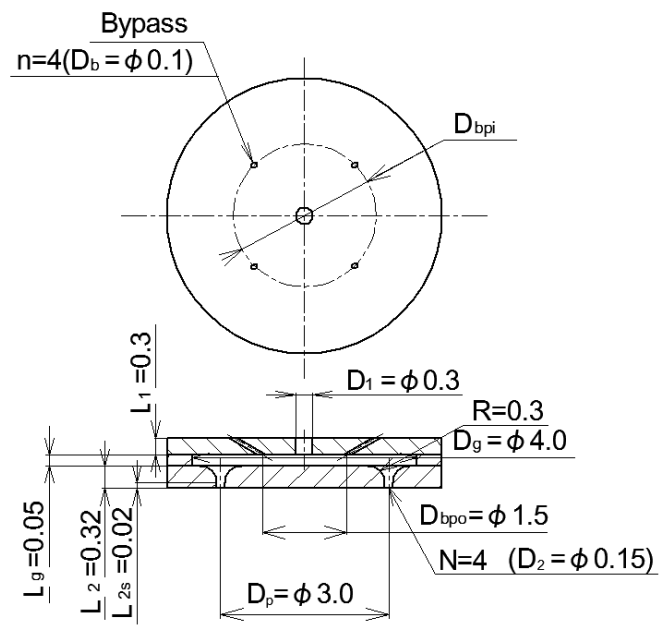

ematic of test nozzle. 


\section{Results and discussion}

\section{Effects of nozzle hole inlet and outlet shapes on atomization characteristics}

The effects of the nozzle hole inlet and outlet shapes on the disintegration behavior of the spray are presented in Fig.7. Since the spray of Nozzle-S, $R_{d i}$ atomizes significantly, a large number of small droplets are suspended and form a mist at the surroundings of the ejected spray. The photographic images of the spray are taken against a white background and the boundaries between the ejected spray and the background are indistinct. The spread of the spray of Nozzle-S, $R_{d i}$ is larger than that of Nozzle-S, $S$ and Nozzle-S, $R_{d o}$.

The effects of the nozzle hole inlet and outlet shapes on breakup length and spray angle are shown in Figs. 8 and 9 , respectively. It is well known that when the breakup length is short and the spray angle is large, excellent atomization characteristics are obtained. As shown in Fig.8, the breakup length of Nozzle-S, $R_{\text {di }}$ is the shortest. Although the breakup lengths of Nozzle-S, Rdi and Nozzle-S, S only differ by $0.5 \mathrm{~mm}$, it is apparent that the breakup length is shortest when the spray is injected from a small hole diameter of $0.15 \mathrm{~mm}$. Figure 7 shows that as injection pressure is increased, the spray angle increases independent of the nozzle hole geometry. The spray angle of Nozzle-S, $R_{d i}$ becomes approximately twice that of the other nozzles for the overall injection pressure.

\section{Effect of including bypass inclination on spray characteristics}

The effect of the inclusion of an inclined bypass on the disintegration behavior of the spray is shown in Fig.10. The spread of the spray of Nozzle-S $S_{b c i}, R_{d i}$, which has the inclined bypass, is wider compared to that of Nozzle-S, $R_{d i}$, which comprises the bypass that is not inclined. It is over $70^{\circ}$ at the maximum injection pressure of $\mathrm{P}_{\mathrm{i} \text { max. }}=10 \mathrm{MPa}$. The effects of the inclusion of the inclined bypass on the spray angle and the Sauter mean diameter are shown in Figs. 11 and 12, respectively. As seen in Fig.11, the spray angle monotonically increases with an increasing injection pressure. The spray angle of Nozzle-S $\mathrm{dci}, \mathrm{R}_{\mathrm{di}}$, for which the bypass was inclined, is $50 \%$ larger than that of Nozzle$S, R_{d i}$ for any arbitrary injection pressure value. Figure 12 shows that for Nozzle-S, $R_{d i}$, as the injection pressure is increased to the maximum value of $10 \mathrm{MPa}$, the Sauter mean diameter decreases monotonically, whereas for

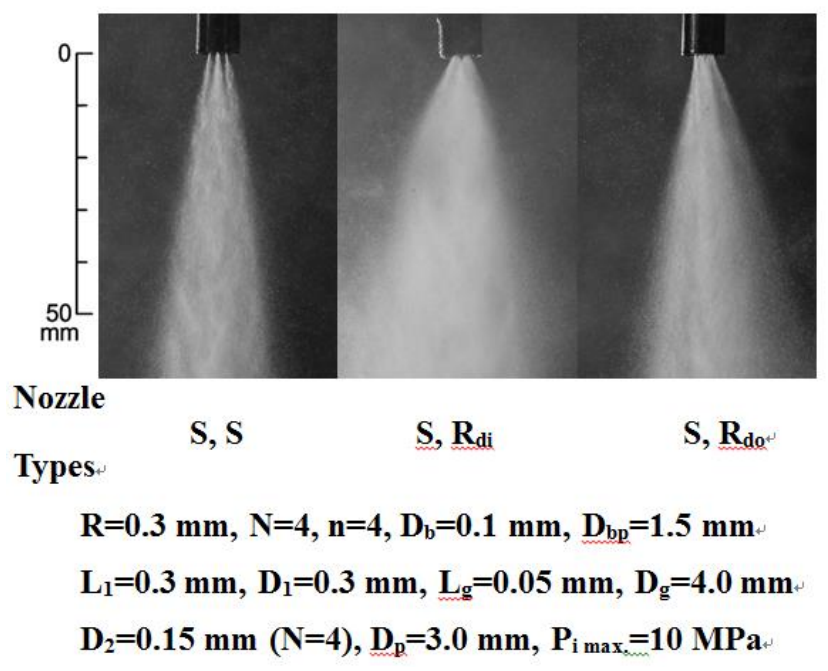

Figure 7. Effects of nozzle hole inlet and outlet shapes on disintegration behavior of spray.

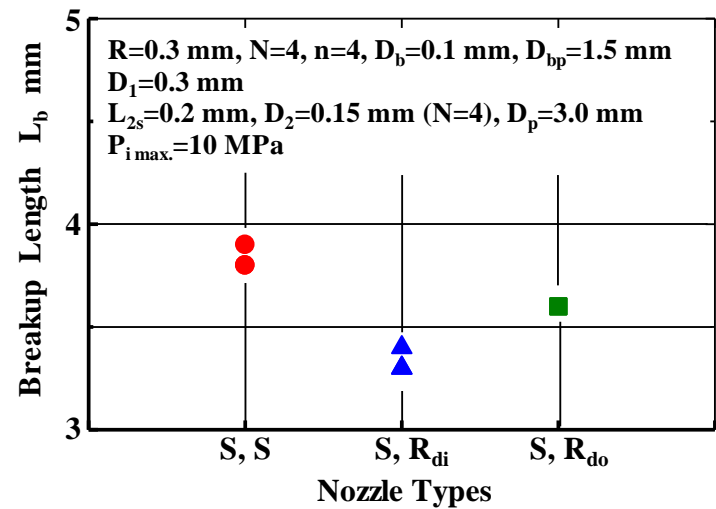

Figure 8. Effects of nozzle hole inlet and outlet shapes on breakup length.

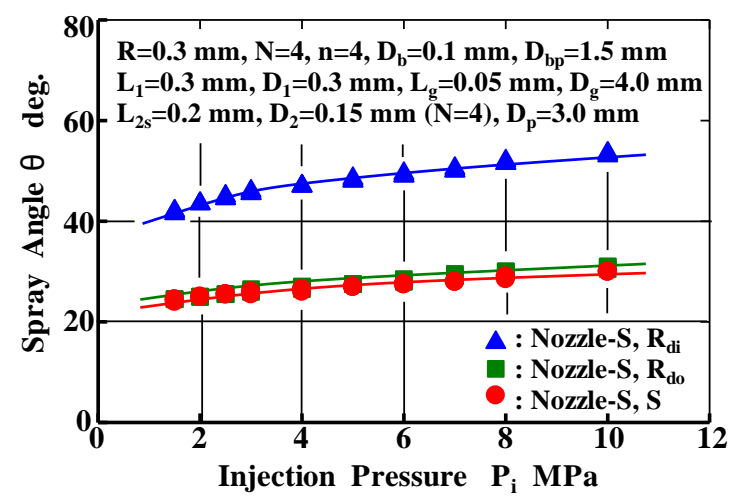

Figure 9. Effects of nozzle hole inlet and outlet shapes on spray angle. 

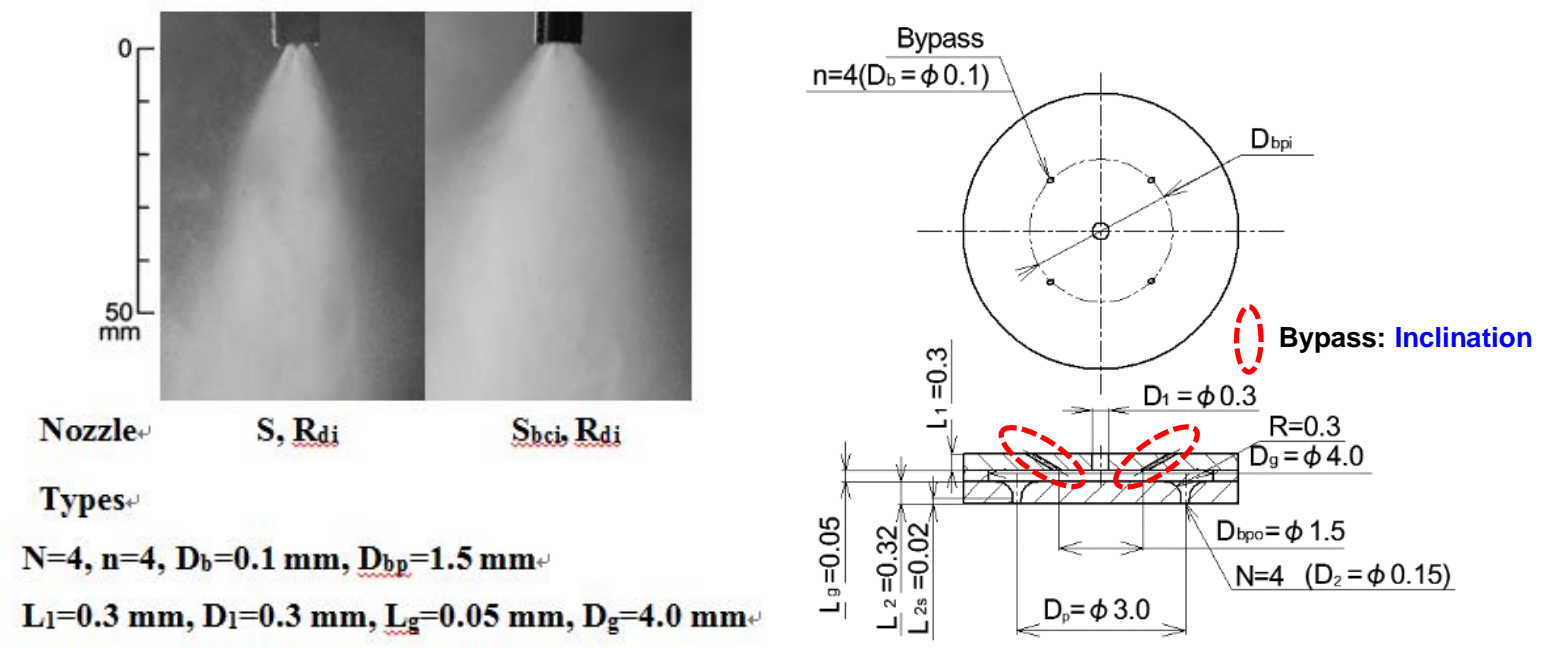

Types

$\mathrm{N}=4, \mathrm{n}=4, \mathrm{D}_{\mathrm{b}}=0.1 \mathrm{~mm}, \mathrm{D}_{\mathrm{bp}}=1.5 \mathrm{~mm}$

$\mathrm{L}_{\mathrm{l}}=0.3 \mathrm{~mm}, \mathrm{D}_{\mathrm{l}}=0.3 \mathrm{~mm}, \mathrm{~L}_{\mathrm{g}}=0.05 \mathrm{~mm}, \mathrm{D}_{\mathrm{g}}=4.0 \mathrm{~mm}$

$\mathrm{L}_{2}=0.3 \mathrm{~mm}, \mathrm{D}_{2}=0.15 \mathrm{~mm}(\mathrm{~N}=4), \mathrm{D}_{\mathrm{p}}=3.0 \mathrm{~mm}$

$P_{\text {imax. }}=10 \mathrm{MPa}$

Figure 10. Effect of inclusion of inclined bypass on disintegration behavior of spray.

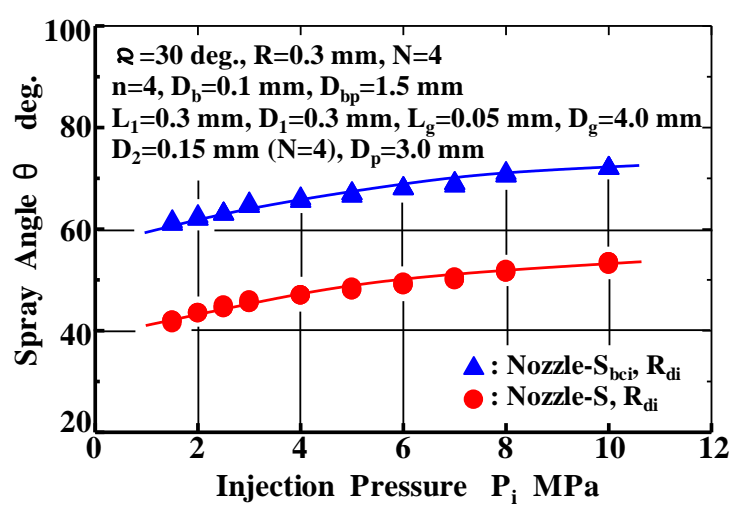

Figure 11. Effects of inclusion of inclined bypass on spray angle.

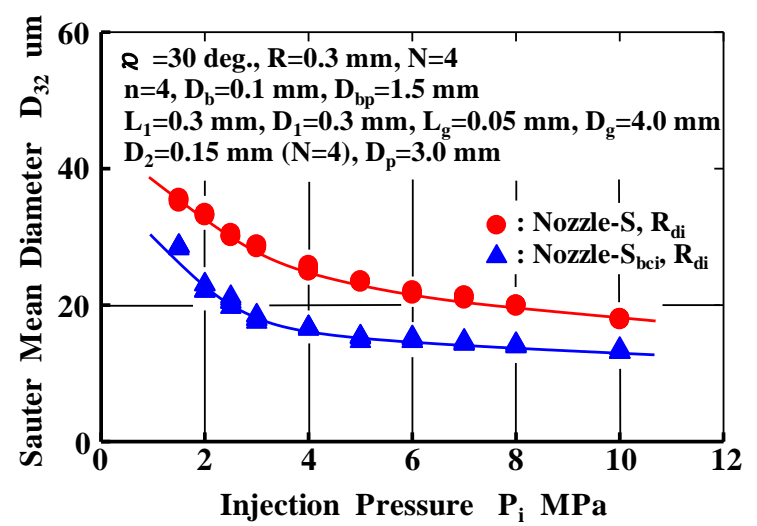

Figure 12. Effects of inclusion of inclined bypass on Sauter mean diameter.

Nozzle-S $S_{b c i}, R_{d i}$, the Sauter mean diameter decreases with increasing injection pressure only until $5 \mathrm{MPa}$, after which it plateaus. Therefore, any further increases in injection pressure, up until a maximum of $10 \mathrm{MPa}$, causes little to no changes in the Sauter mean diameter of Nozzle-Sbci, $R_{d i}$. For the pressure regions tested, the Sauter mean diameter of Nozzle-S bci, $_{\text {di }}$ was smaller than that of Nozzle-S, $R_{d i}$. Hence, it can be concluded that an inclined bypass is an effective method for enhancing spray atomization and improving spray characteristics. A possible explanation for this is that when the bypass is inclined towards the radial direction, it is possible that strong disturbance like the collapse of cavitation bubbles and strong swirling flow occurs inside the gap and four nozzle holes. Moreover, it is expected that momentum towards the radial direction is retained, owing to the swirling flow. Therefore, Nozzle-Sbci, $R_{d i}$ can be used to provide improved spray characteristics.

\section{Effect of bypass inclination on spray characteristics}

The effects of different bypass inclination angles on the disintegration behavior of the spray are presented in Fig.13. The spread of the spray was the widest for the bypass inclination angle of $\alpha=30^{\circ}$ while for $\alpha=60^{\circ}$, the spread was the narrowest. For $\alpha=30^{\circ}$, a large number of small droplets forming a mist were observed within and around the spray. It can be seen that a homogeneous spray is obtained.

Figure 14 shows the effect of the bypass inclination angle on breakup length. The breakup length for the bypass inclination angle of $\alpha=30^{\circ}$ was relatively short. As the inclination angle was increased, the breakup length also increased from a microscopic point of view. 


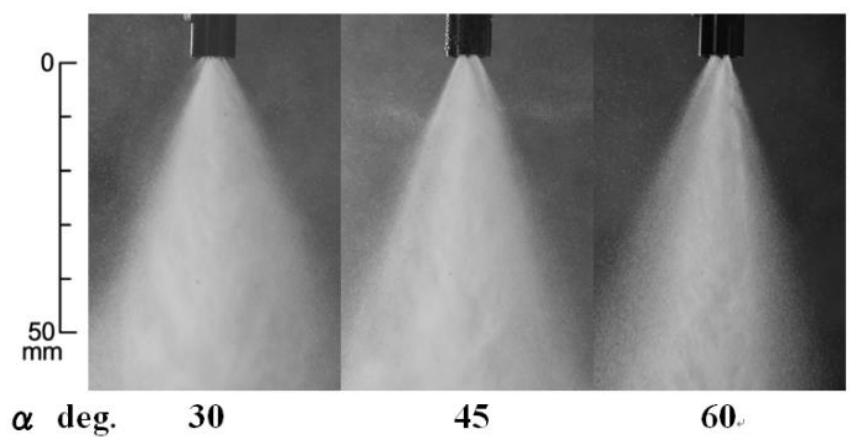

Nozzle- $S_{b c i}, S, N=4, n=4, D_{b}=0.1 \mathrm{~mm}, D_{b p}=1.5 \mathrm{~mm}$

$\mathrm{L}_{1}=0.3 \mathrm{~mm}, \mathrm{D}_{1}=0.3 \mathrm{~mm}, \mathrm{~L}_{\mathrm{g}}=0.05 \mathrm{~mm}, \mathrm{D}_{\mathrm{g}}=4.0 \mathrm{~mm}$

$\mathrm{L}_{2}=0.2 \mathrm{~mm}, \mathrm{D}_{2}=0.15 \mathrm{~mm}(\mathrm{~N}=4), \mathrm{D}_{\mathrm{p}}=3.0 \mathrm{~mm}$

$P_{\text {max }_{\text {ax }}=10 \mathrm{MPa}}$

Figure 13. Effects of different bypass inclination angles on disintegration behavior of spray.

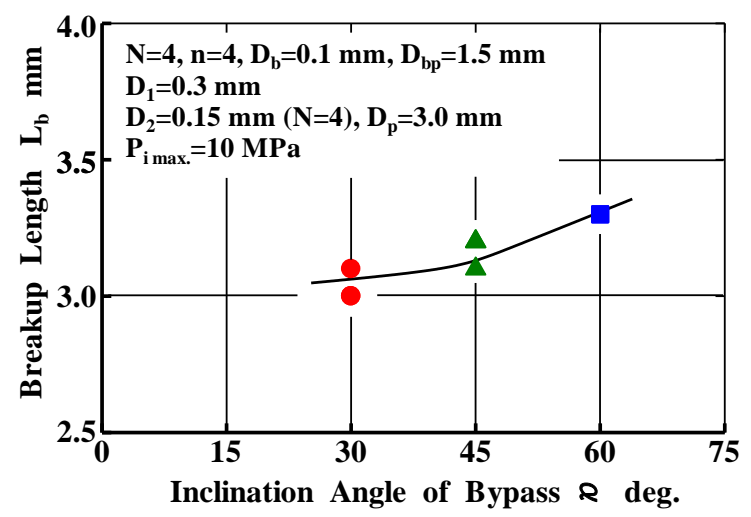

Figure 14. Effect of bypass inclination angle on breakup length.

\section{Conclusions}

[1] The spray angle of Nozzle-S, $R_{\mathrm{di}}$, which comprised a rounded nozzle hole inlet, was approximately twice the spray angles of Nozzle-S, S and Nozzle-S, Rdo.

[2] An inclined bypass strongly affected the spray characteristics of the nozzle. The spray angle for Nozzle-Sdci, $R_{d i}$, which consisted of the inclined bypass, was approximately $50 \%$ larger than that for Nozzle-S, Rdi, which did not include an inclined bypass. The Sauter mean diameter of Nozzle-Sbci, $R_{d i}$ was smaller than that of Nozzle-S, Rdi.

[3] For the bypass inclination angle of $\alpha=30^{\circ}$, the spread of the spray was the widest obtained. A large number of small droplets forming a mist were observed and a homogeneous spray was obtained.

\section{Acknowledgements}

This research was partly supported by the Japan Society for the Promotion of Science (JSPS) KAKENHI (C) Grant Number 15K05847 and also partly supported by the Ministry of Education, Culture, Sports, Science and Technology (MEWT) MEXT-Supported Program for the Strategic Research Foundation at Private Universities. The authors wish to express their thanks for the supporting for this research.

\section{Nomenclature}

$D_{1} \quad$ hole diameter upstream from gap [mm]

$\mathrm{D}_{2} \quad$ hole diameter downstream from gap [mm]

$D_{32} \quad$ Sauter mean diameter $[\mu \mathrm{m}]$

$\mathrm{D}_{\mathrm{b}} \quad$ bypass diameter [mm]

$D_{b p} \quad$ pitch circle diameter of bypass $[\mathrm{mm}]$

$D_{\text {bpi }} \quad$ pitch circle diameter of bypass at inlet of nozzle hole [mm]

$D_{\mathrm{bpo}} \quad$ pitch circle diameter of bypass at outlet of nozzle hole [mm]

$\mathrm{D}_{\mathrm{g}} \quad$ gap diameter [mm]

$D_{p} \quad$ pitch circle diameter of nozzle hole [mm]

$\mathrm{L}_{1} \quad$ hole length upstream from gap [mm]

$\mathrm{L}_{2} \quad$ hole length downstream from gap [mm]

L2s straight pipe length downstream from gap [mm]

$\mathrm{Lb}_{\mathrm{b}} \quad$ breakup length [mm]

$\mathrm{Lg} \quad$ gap length [mm]

$\mathrm{n}$ bypass number [number]

$\mathrm{N} \quad$ hole number [number]

$\mathrm{Pi}_{\mathrm{i}} \quad$ injection pressure [MPa]

$\mathrm{P}_{\mathrm{i} \text { max. }} \quad$ maximum injection pressure $[\mathrm{MPa}]$

$\mathrm{R} \quad$ round chamfer [mm]

$\mathrm{R}_{\mathrm{di}} \quad$ inlet shape of nozzle hole downstream from gap (round chamfer)

Rdo outlet shape of nozzle hole downstream from gap (round chamfer)

$\mathrm{S} \quad$ inlet and outlet shapes of nozzle hole downstream from gap (sharp edged)

a inclination angle of bypass [deg.] 


\section{Superscripts}

$\begin{array}{ll}1 & \text { upstream } \\ 2 & \text { downstream } \\ 2 s & \text { straight pipe length } \\ 32 & \text { volume / surface area } \\ \text { b } & \text { bypass, breakup } \\ \text { bp } & \text { pitch circle diameter of bypass } \\ \text { bpi } & \text { pitch circle diameter of bypass at inlet } \\ \text { bpo } & \text { pitch circle diameter of bypass at outlet } \\ \text { di } & \text { inlet shape of nozzle hole } \\ \text { do } & \text { outlet shape of nozzle hole } \\ \text { g } & \text { gap } \\ \text { i } & \text { injection } \\ \text { i max. } & \text { maximum injection pressure }\end{array}$

\section{References}

[1] Chaves, H, Knapp, M., Kubitzek, A., Obermeier, F. and Schneider, T., 1995, SAE Technical Paper: No. 950290, pp.645-657.

[2] Tamaki, N., Nishida, K., Shimizu, M. and Hiroyasu, H., 1998, Atomization and Sprays, 8 (2), pp.179-197.

[3] Arcoumanis, C. and Gavaises, M., July 6-8, 1998, Proceedings 14th European Conference on Liquid Atomization and Spray Systems.

[4] Tamaki, N., Shimizu, M. and Hiroyasu, H., July 16-20, 2000, Proceedings Eighth Internal Conference on Liquid Atomization and Spray Systems.

[5] Tamaki, N., Shimizu, M. and Hiroyasu, H., 2001, Atomization and Sprays, 11 (2), pp.125-137.

[6] Tamaki, N. and Shimizu, M., September 9-11, 2002, Proceedings 18th European Conference on Liquid Atomization and Spray Systems.

[7] Tamaki, N., July 26-30, 2009, Proceedings 11th Internal Conference on Liquid Atomization and Spray Systems.

[8] Tamaki, N., Kato, A., Kato, K. and Imano, K., Sept. 6-8, 2010, Proceedings 23rd European Conference on Liquid Atomization and Spray Systems.

[9] Tamaki, N. and Katakami, K., Sept. 2-6, 2012, Proceedings 12th Internal Conference on Liquid Atomization and Spray Systems.

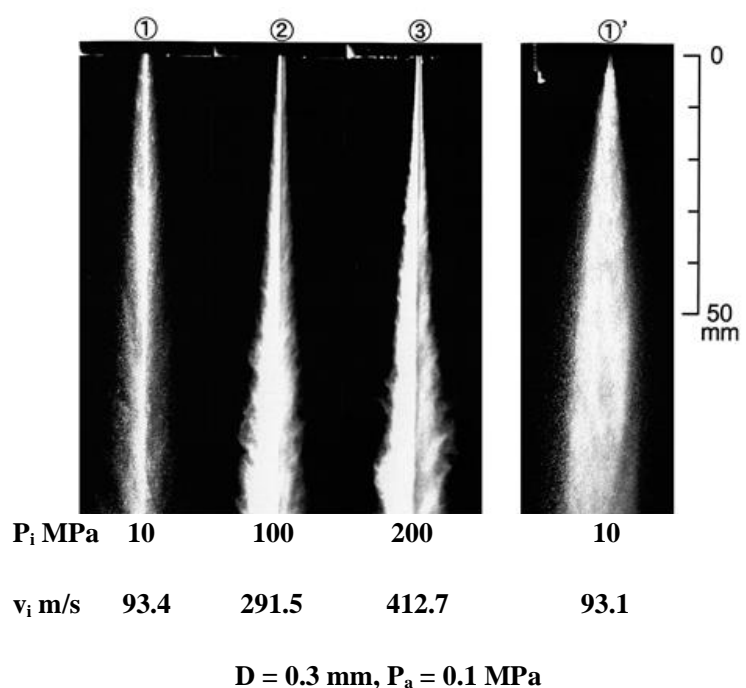

(a) Single Hole Nozzle.

(b) Atomization Enhancement Nozzle.

Appendix Figure 1. Disintegration behavior of spray at super-high injection pressure [4].

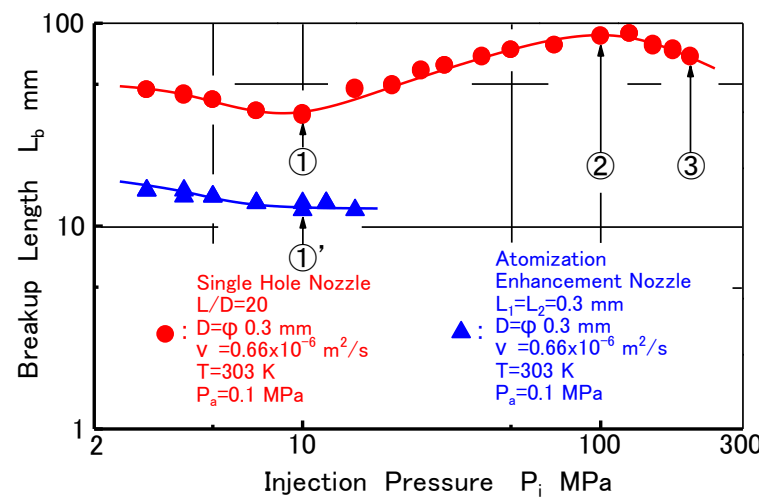

Appendix Figure 2. Comparison of breakup length [4].

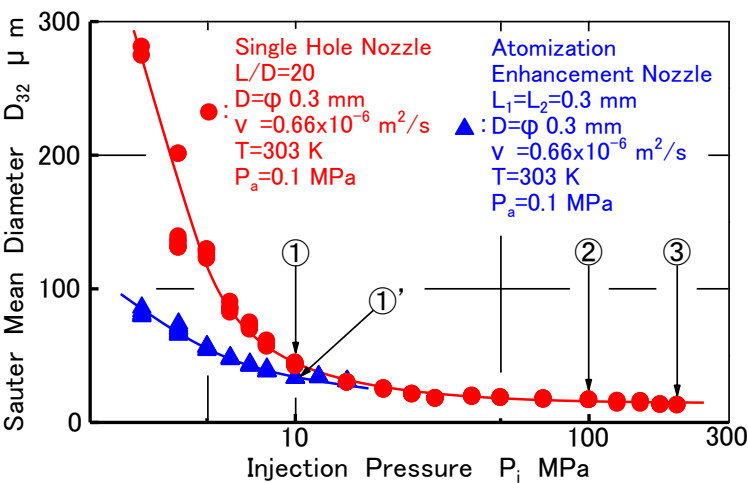

Appendix Figure 3. Comparison of Sauter mean diameter [4]. 


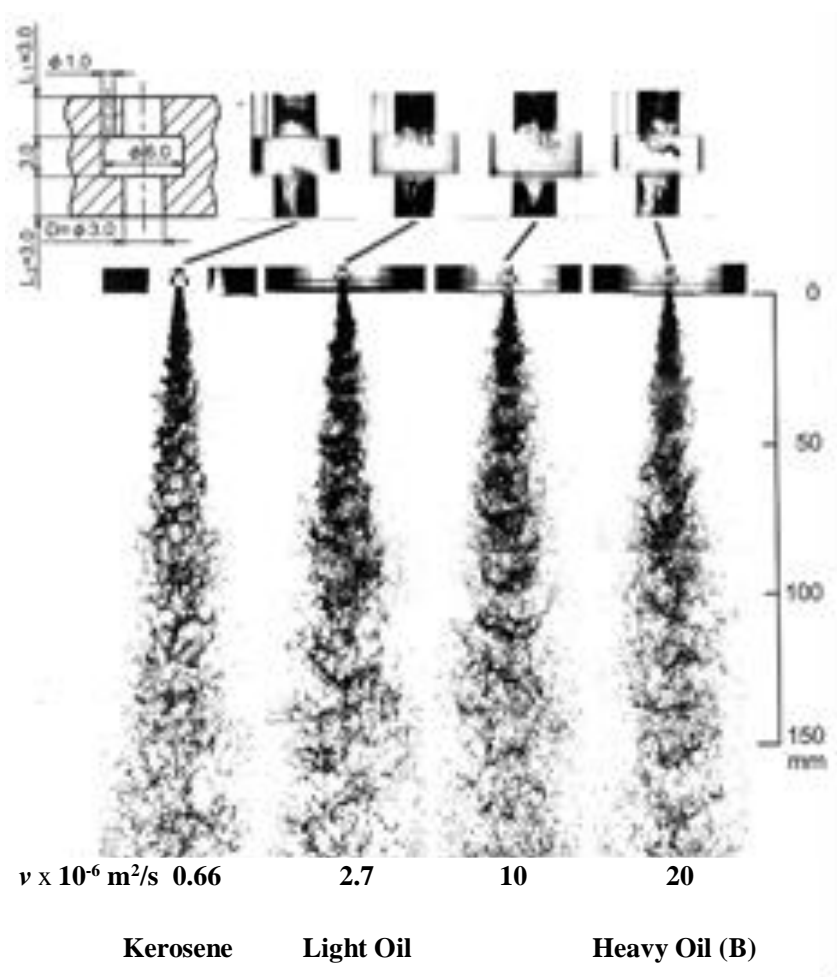

$D=3.0 \mathrm{~mm}, P_{i}=1.5 \mathrm{MPa}, T_{a}=313 \mathrm{~K}, P_{a}=0.1 \mathrm{MPa}$

Appendix Figure 4. Effect of kinematic viscosity of liquid on disintegration behaviour of spray (Magnified nozzle) [6].

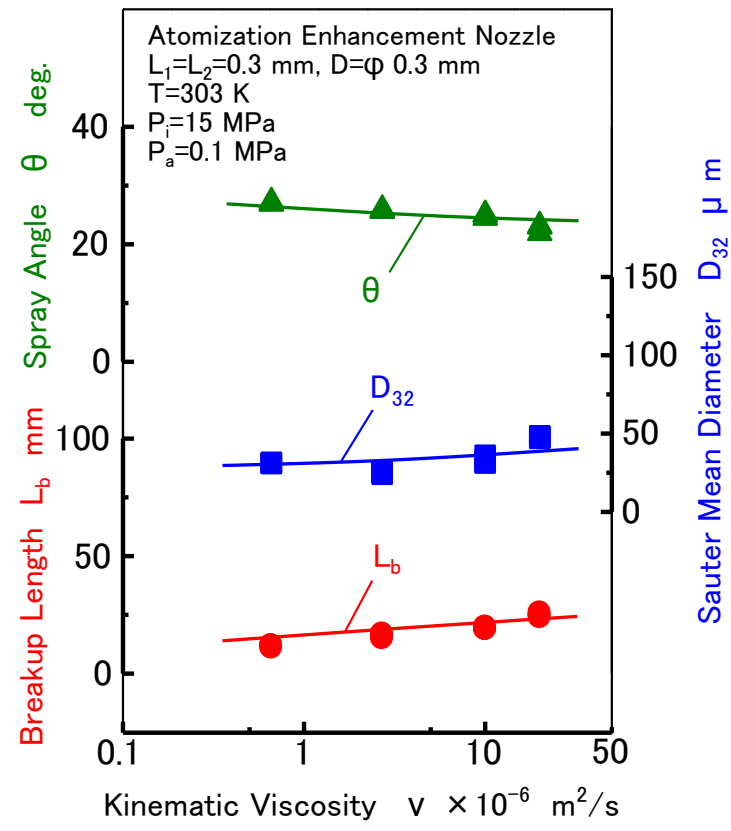

Appendix Figure 6. Effect of kinematic viscosity of liquid on spray characteristics (Actual size nozzle) [6].

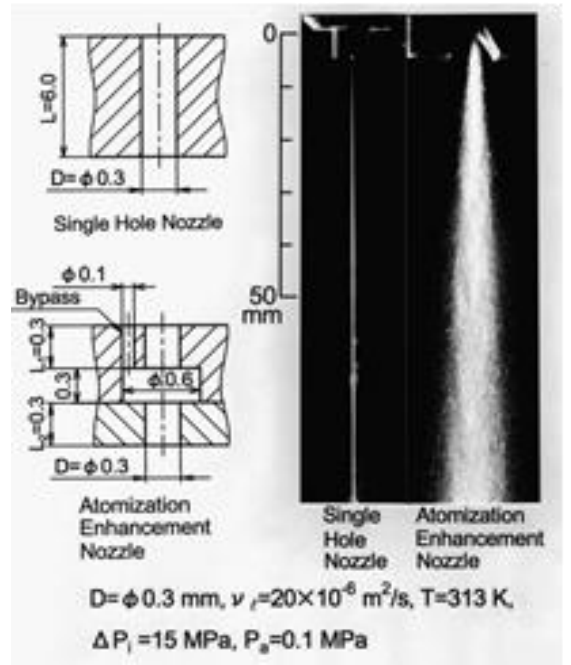

Appendix Figure 5. Atomization of high-viscosity liquid (Heavy Oil B) (Actual size nozzle) [6]

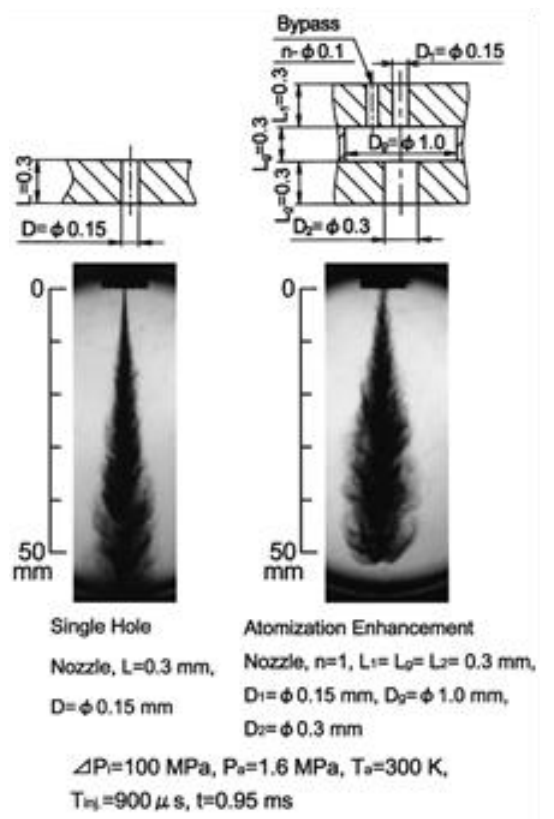

Appendix Figure 7. Atomization of intermittent spray (Light Oil) (Actual size nozzle) [7] 